\title{
Induction effects of geomagnetic disturbances in the geo-electric field variations at low latitudes
}

\author{
Vafi Doumbia ${ }^{1}$, Kouadio Boka ${ }^{1}$, Nguessan Kouassi ${ }^{1}$, Oswald Didier Franck Grodji ${ }^{1}$, Christine Amory-Mazaudier ${ }^{2,3}$, \\ and Michel Menvielle ${ }^{4}$ \\ ${ }^{1}$ Laboratoire de Physique de l'Atmosphère, Université Felix Houphouet Boigny, Abidjan, Côte d'Ivoire \\ ${ }^{2}$ LPP, CNRS, Ecole polytechnique, UPMC Univ Paris 06, Univ. Paris-Sud, Observatoire de Paris, Université Paris-Saclay, \\ Sorbonne Universités, PSL Research University, 4 place Jussieu, 75252 Paris, France \\ ${ }^{3}$ International Center for Theoretical Physics, Trieste, Italy \\ ${ }^{4}$ Université Versailles St-Quentin; CNRS/INSU, LATMOS-IPSL, 4 Avenue de Neptune, \\ 94107 Saint-Maur-des-Fossés, France
}

Correspondence to: Vafi Doumbia (vafid@yahoo.fr)

Received: 1 August 2016 - Revised: 23 October 2016 - Accepted: 22 November 2016 - Published: 4 January 2017

\begin{abstract}
In this study we examined the influences of geomagnetic activity on the Earth surface electric field variations at low latitudes. During the International Equatorial Electrojet Year (IEEY) various experiments were performed along $5^{\circ} \mathrm{W}$ in West Africa from 1992 to 1995 . Among other instruments, 10 stations equipped with magnetometers and telluric electric field lines operated along a meridian chain across the geomagnetic dip equator from November 1992 to December 1994. In the present work, the induced effects of space-weather-related geomagnetic disturbances in the equatorial electrojet (EEJ) influence area in West Africa were examined. For that purpose, variations in the north-south $\left(E_{x}\right)$ and east-west $\left(E_{y}\right)$ components of telluric electric field were analyzed, along with that of the three components $(H, D$ and $Z$ ) of the geomagnetic field during the geomagnetic storm of 17 February 1993 and the solar flare observed on 4 April 1993. The most important induction effects during these events are associated with brisk impulses like storm sudden commencement (ssc) and solar flare effect (sfe) in the geomagnetic field variations. For the moderate geomagnetic storm that occurred on 17 February 1993, with a minimum Dst index of $-110 \mathrm{nT}$, the geo-electric field responses to the impulse around 11:00 LT at LAM are $E_{x}=520 \mathrm{mV} \mathrm{km}^{-1}$ and $E_{y}=400 \mathrm{mV} \mathrm{km}^{-1}$. The geo-electric field responses to the sfe that occurred around 14:30 LT on 4 April 1993 are clearly observed at different stations as well. At LAM the crest-to-crest amplitude of the geo-electric field components associated with the sfe are $E_{x}=550 \mathrm{mV} \mathrm{km}^{-1}$ and
\end{abstract}

$E_{y}=340 \mathrm{mV} \mathrm{km}^{-1}$. Note that the sfe impact on the geoelectric field variations decreases with the increasing distance of the stations from the subsolar point, which is located at about $5.13^{\circ} \mathrm{N}$ on 4 April. This trend does not reflect the sfe increasing amplitude near the dip equator due the high Cowling conductivity in the EEJ belt.

Keywords. Geomagnetism and paleomagnetism (geomagnetic induction)

\section{Introduction}

Intense space weather events like geomagnetic storms and substorms are potential sources of electric induction within the earth. These events cause intense geomagnetic field variations which are expected to induce electric fields and currents in the conducting layers of the Earth lithosphere. Disruptions of technological systems dues to the "geomagnetically induced currents (GICs)" have been known in the Scandinavian countries since the mid-19th century (Pulkkinen, 2003). Due to these negative impacts on technological devices, the GICs have been mostly investigated at high latitudes (Pulkkinen et al., 2001, 2003a, b, 2007; Pirjola, 2000, 2002, 2005; Wik et al., 2008, 2009). Magnetosphere-ionosphere coupling through geomagnetic field lines generates intense currents such as auroral electrojets in the high-latitude ionosphere. These currents are extremely enhanced during geomagnetic storms and substorms and cause very intense geomagnetic 
field variations. As consequence, intense GICs cause disturbances in technological devices like telecommunication and pipe lines, power grids, and transformers.

Kappenman (2003) demonstrated the risk of large GIC occurrences associated with large geomagnetic impulses like storm sudden commencement (ssc) at low- and midlatitudes. There are reports of GIC causing perturbation in technological structures in the mid- and low latitudes (Ngwira et al., 2008; Torta et al., 2012; Trivedi et al., 2007). In addition to the global-scale geomagnetic disturbances due to currents in the magnetosphere, it is now well established that disturbances that originate from the high-latitude ionospheric currents extend toward mid- and low latitudes during geomagnetic storms. The effects of electric field prompt penetrations and the disturbance dynamo (Blanc and Richmond, 1980; Fambitakoye et al., 1990; Zaka et al., 2010) as well as the mechanisms of different processes have been thoroughly investigated. However, only little research work has been devoted to the induction effects of space-weather-related geomagnetic field disturbances at low latitudes. Most studies on the issue have mainly focused on magnetically quiet-time induction effects of the equatorial electrojet (Fambitakoye, 1973; Ducruix et al., 1977). Nevertheless, to a large extent, most of those studies have concluded that there is a very weak induction effect of the equatorial electrojet (EEJ). However, measurements of GICs in electric power transformers at low latitudes in Brazil were analyzed by Trivedi et al. (2007). For the geomagnetic storm period of 7 to 10 November 2004, they reported values of the GIC that attain 15A. In a recent study, Ngwira et al. (2013) investigated the global behavior of the horizontal geomagnetic field and the induced geo-electric field fluctuations during extreme geomagnetic events. Among other things, the latitude threshold boundary was examined. From this study, Ngwira et al. (2013) found the largest perturbations in the geomagnetic and geo-electric fields at high latitudes and an important enhancement in the EEJ influence area. Carter et al. (2015) also analyzed potential induction effects of the so-called interplanetary shock events (ssc and solar flare effect, sfe) on the basis of the time derivatives of geomagnetic field variations. They emphasized potential threats of important GICs during these shock events near the geomagnetic equator due to enhancements of geomagnetic disturbances caused by the EEJ in this area.

The present work aims at examining the induced effects of space-weather-related geomagnetic disturbances in the EEJ influence area in West Africa. For that purpose, variations in the north-south $\left(E_{x}\right)$ and east-west $\left(E_{y}\right)$ components of telluric (geo-electric) field are analyzed, along with that of the three components $(H, D$ and $Z)$ of the geomagnetic field during the geomagnetic storm of 17 February 1993 and the solar flare on 4 April 1993.

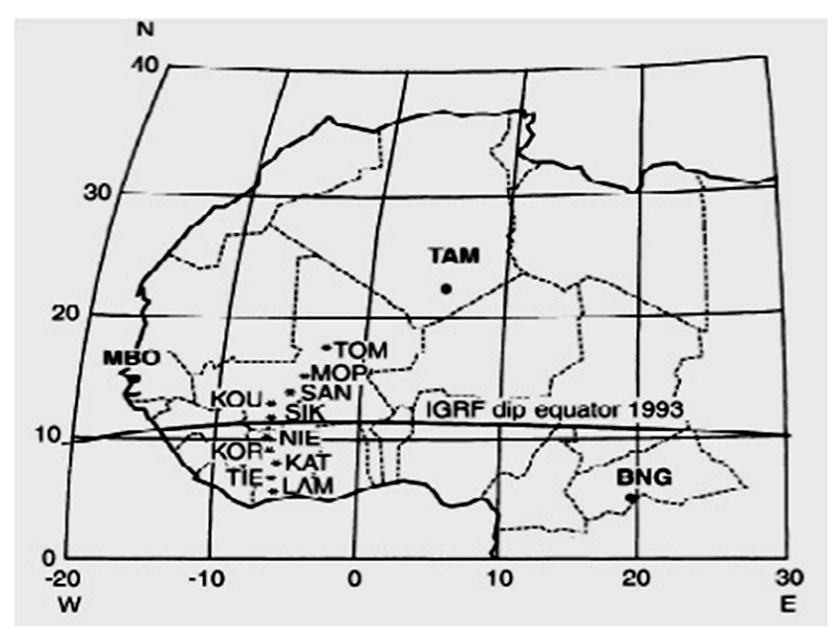

Figure 1. The West African network of 10 stations for the geomagnetic and telluric field measurements during the International Equatorial Electrojet Year (IEEY).

\section{Data and analysis}

In the framework of the International Equatorial Electrojet Year (IEEY; 1992-1995), many different instruments were deployed in different longitude sectors (Arora et al., 1993; Amory-Mazaudier et al., 1993). On that occasion, variations in the geomagnetic field and various parameters of the lowlatitude ionosphere were monitored with a view to deepening our knowledge on equatorial and low-latitude electromagnetic phenomena and underlying physical processes. Specifically, in West Africa, a network of three ionosondes, a Fabry-Pérot interferometer (Vila et al., 1998) and an HF radar (Blanc and Houngninou, 1998) were set up. In addition to those instruments, a meridian chain of 10 magnetic and telluric stations was deployed across the geomagnetic dip equator, from Lamto (Côte d'Ivoire, $-6.30^{\circ}$ dip latitudes) to Tombouctou (Mali, $+6.76^{\circ}$ dip latitudes), along the $5^{\circ} \mathrm{W}$ meridian. Figure 1 shows the IEEY network of magnetic and telluric stations in West African (Amory-Mazaudier et al., 1993; Doumouya et al., 1998; and Vassal et al., 1998). The coordinates of the stations are given in Table 1 . These stations collected variations in the horizontal northward $(H)$, eastward $(D)$ and vertical $(Z)$ components of the geomagnetic field, as well as the north-south $\left(E_{x}\right)$ and east-west $\left(E_{y}\right)$ components of the geo-electric field variations from November 1992 to December 1994 (Doumouya et al., 1998 and Vassal et al., 1998). The $H$ and $D$ components were measured with suspended magnet variometers, and the $Z$ component was recorded with a fluxgate magnetometer. The $E_{x}$ and $E_{y}$ components of the geo-electric field were measured using electric lines of $200 \mathrm{~m}$. The measurements of all components were performed at a sampling rate of $1 \mathrm{~min}$.

As quiet-time geomagnetic field variations have been used to study the EEJ (Doumouya et al., 1998), geomagnetically 
Table 1. Geographic coordinates of the magnetic stations installed along the meridian $5^{\circ} \mathrm{W}$ in West Africa during the International Equatorial Electrojet Year.

\begin{tabular}{lcrrr}
\hline & & \multicolumn{2}{c}{ Geographic } & \\
\cline { 3 - 4 } Stations & Station codes & $\begin{array}{r}\text { Latitude } \\
\left({ }^{\circ} \mathrm{N}\right)\end{array}$ & $\begin{array}{r}\text { Longitude } \\
\left({ }^{\circ} \mathrm{W}\right)\end{array}$ & $\begin{array}{r}\text { Dip latitude } \\
\left.{ }^{\circ} \mathrm{N}\right)\end{array}$ \\
\hline Tombouctou & TOM & 16.73 & 3.00 & 6.76 \\
Mopti & MOP & 14.51 & 4.09 & 4.02 \\
San & SAN & 13.24 & 4.88 & 2.45 \\
Koutiala & KOU & 12.36 & 5.45 & 1.38 \\
Sikasso & SIK & 11.34 & 5.71 & 0.12 \\
Nielle & NIE & 10.20 & 5.64 & -1.30 \\
Korhogo & KOR & 9.34 & 5.43 & -2.38 \\
Katiola & KAT & 8.18 & 5.043 & -3.85 \\
Tiebissou & TIE & 7.22 & 5.243 & -5.04 \\
Lamto & LAM & 6.23 & 5.02 & -6.30 \\
\hline
\end{tabular}

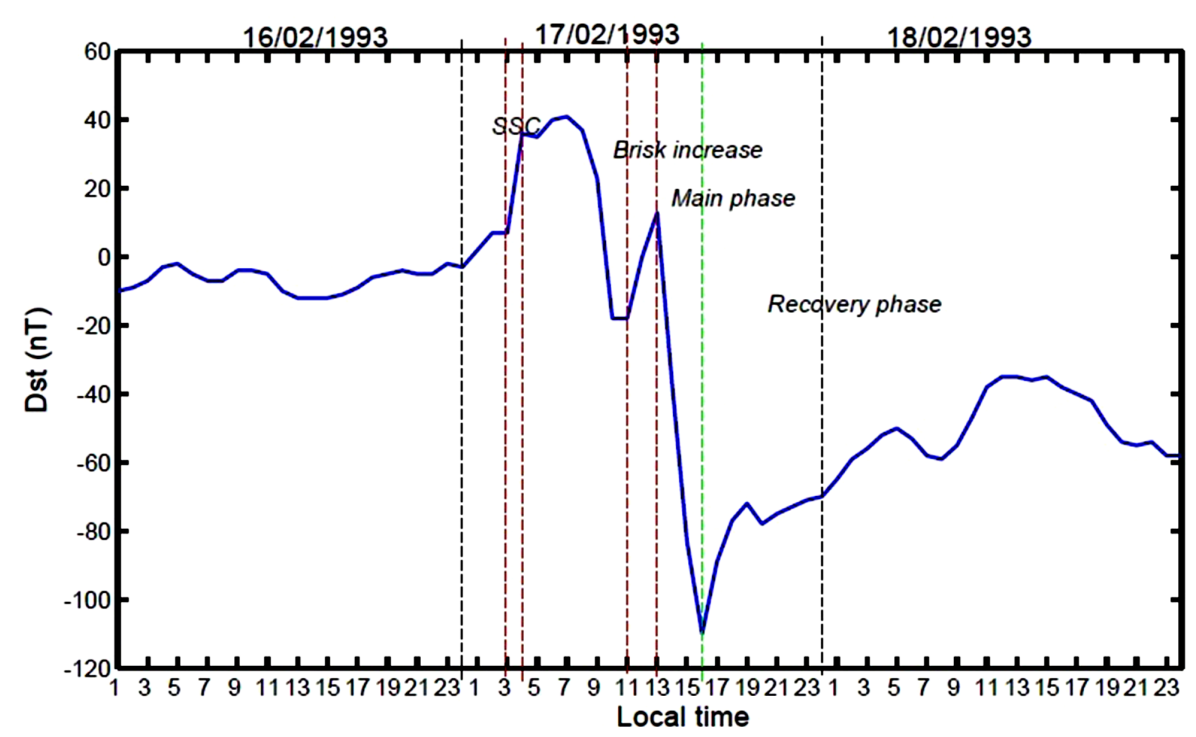

Figure 2. The Dst index from 16 to 18 February 1993. An ssc at 03:00 LT starts the process of a moderate geomagnetic storm on 17 February 1993 with a daily Am $=64 \mathrm{nT}$. At 11:00 LT another brisk increase started. During the main phase of the storm, the Dst minimum value is $-110 \mathrm{nT}$ around 16:00 LT. The Dst data were copied from the website http://wdc.kugi.kyoto-u.ac.jp/dst_final/index.html.

quiet-time variations in the geo-electric field were dedicated to investigating induction effects of the EEJ within the Earth. The first results based on the analyses of geomagnetic field and geo-electric field observations have been published (Vassal et al., 1998). The purpose of the present study is to analyze the effects of geomagnetic disturbances in the geoelectric field variations at low latitudes. Specifically, we examine the effects of the phases of a geomagnetic storm and that of an sfe in the geo-electric field variations in West Africa. To that end, data recorded on 17 February and on 4 April 1993 are considered. On 17 February 1993 a moderate geomagnetic storm occurred with a daily mean value of the Am index of $64 \mathrm{nT}$. In addition the effects of the sfe that occurred around 14:30 LT on 4 April 1993 are examined.

\subsection{Geomagnetic field variations during the 17 February 1993 magnetic storm}

Figure 2 shows the Dst index from 16 to 18 February 1993. On 17 February, a sharp increase in Dst index was observed at 03:00 LT, indicating the ssc, which suggests that the geomagnetic storm process has started. Then an impulsive increase in Dst followed at 11:00 LT. During the main phase of the storm the minimum value of the Dst is about $-110 \mathrm{nT}$ around 16:00 LT. In the storm period, data were available at LAM, NIE, SIK, KOU, SAN, MOP and TOM, but for this study we analyze data from LAM (south), NIE and SIK (near the dip equator), and SAN and TOM (north). 

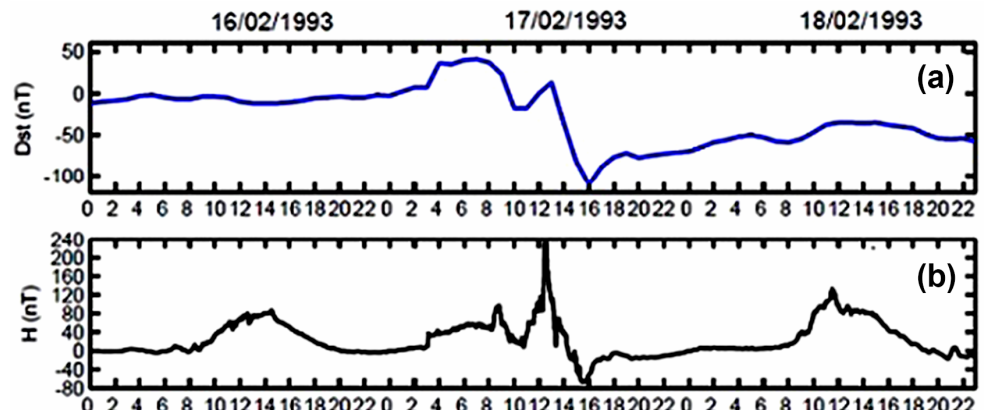

(b)
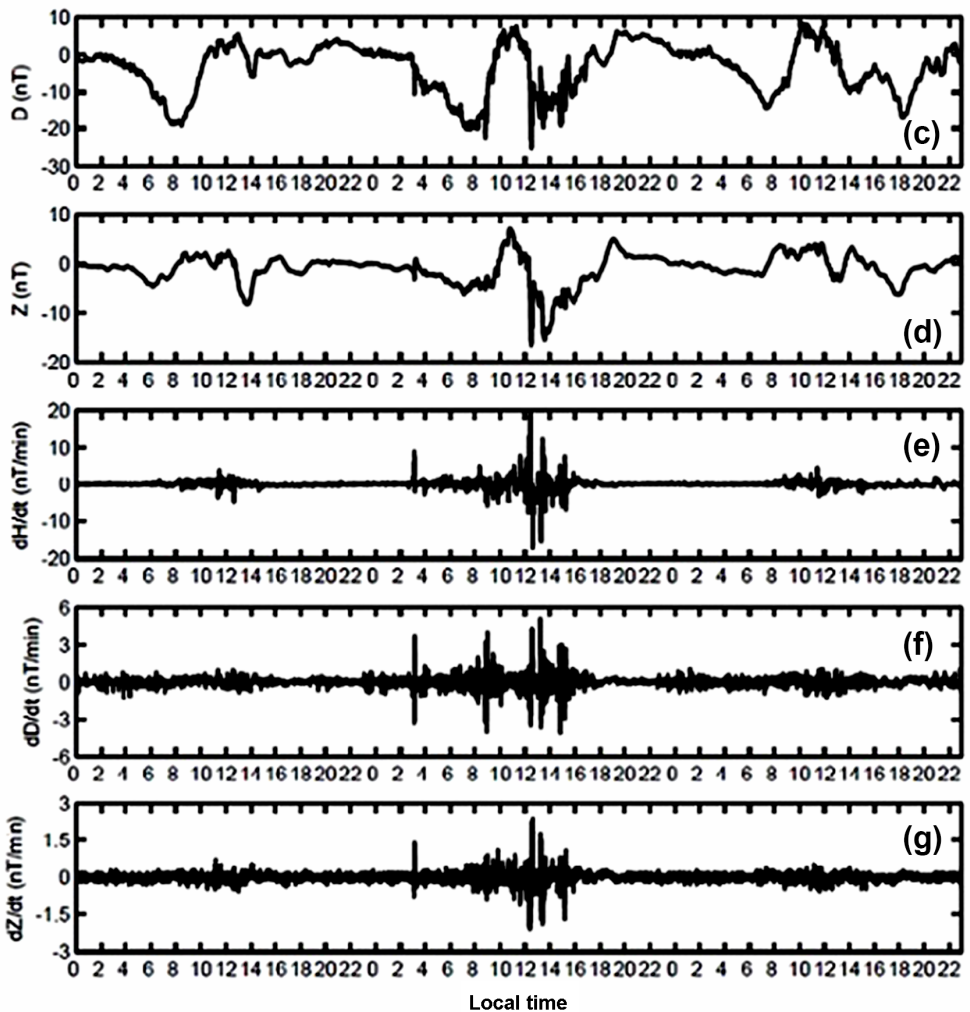

Figure 3. Dst index (a), variations in $H(\mathbf{b}), D(\mathbf{c})$ and $Z(\mathbf{d})$ components, and the time derivatives $\mathrm{d} H / \mathrm{d} t(\mathbf{e}), \mathrm{d} D / \mathrm{d} t(\mathbf{f})$ and $\mathrm{d} Z / \mathrm{d} t(\mathbf{g})$ on 16-18 February 1993 at $\operatorname{SIK}\left(0.12^{\circ}\right.$ dip lat $)$.

As the time derivative $\mathrm{d} \boldsymbol{B} / \mathrm{d} t$ of the magnetic field is a potential indicator of induction current occurrence, we first analyze the time derivatives $\mathrm{d} H / \mathrm{d} t, \mathrm{~d} D / \mathrm{d} t$ and $\mathrm{d} Z / \mathrm{d} t$. These time derivatives are calculated from $1 \mathrm{~min}$ data of the $H$, $D$ and $Z$ components. Figure 3 shows the Dst index and variations in $H, D$ and $Z$ components of the geomagnetic field and their time derivatives $\mathrm{d} H / \mathrm{d} t, \mathrm{~d} D / \mathrm{d} t$ and $\mathrm{d} Z / \mathrm{d} t$ at SIK from 16 to 18 February 1993. On 17 February, disturbances associated with the geomagnetic storm are observed from 03:00 LT to about 18:00 LT. At 03:00 LT, the ssc manifests itself in the sharp increase in $H$. The amplitude of this ssc is about $35 \mathrm{nT}$ in the $H$ component, with a time derivative $\mathrm{d} H / \mathrm{d} t=10 \mathrm{nT} \min ^{-1}$. A secondary impulse observed at 11:00 LT causes an increase of about $120 \mathrm{nT}$ in the $H$ component with a crest-to-crest amplitude of $\mathrm{d} H / \mathrm{d} t=40 \mathrm{nT} \min ^{-1}$. The signatures of the ssc and that the daytime impulse are observed in $D, Z, \mathrm{~d} D / \mathrm{d} t$ and $\mathrm{d} Z / \mathrm{d} t$ as well. Due to the location of SIK near the dip equator, variations in $Z$ and $\mathrm{d} Z / \mathrm{d} t$ are weak. Further fluctuations are observed during all the disturbance periods. However the amplitudes of these fluctuations, including the main phase of the storm, are weaker than the effects of the brisk impulse at 11:00 LT.

Figure $4 \mathrm{a}$, b and c present, respectively, variations in $H, D$ and $Z$ components and their time derivatives $\mathrm{d} H / \mathrm{d} t, \mathrm{~d} D / \mathrm{d} t$ and $\mathrm{d} Z / \mathrm{d} t$ at LAM, NIE, SIK, SAN and TOM. The amplitude of ssc effects during the night does not change much from one station to another. But the daytime impulse reflects the influence of the equatorial electrojet in the $H$ and $Z$ components. In the $H$ component, the daytime impulse effects 

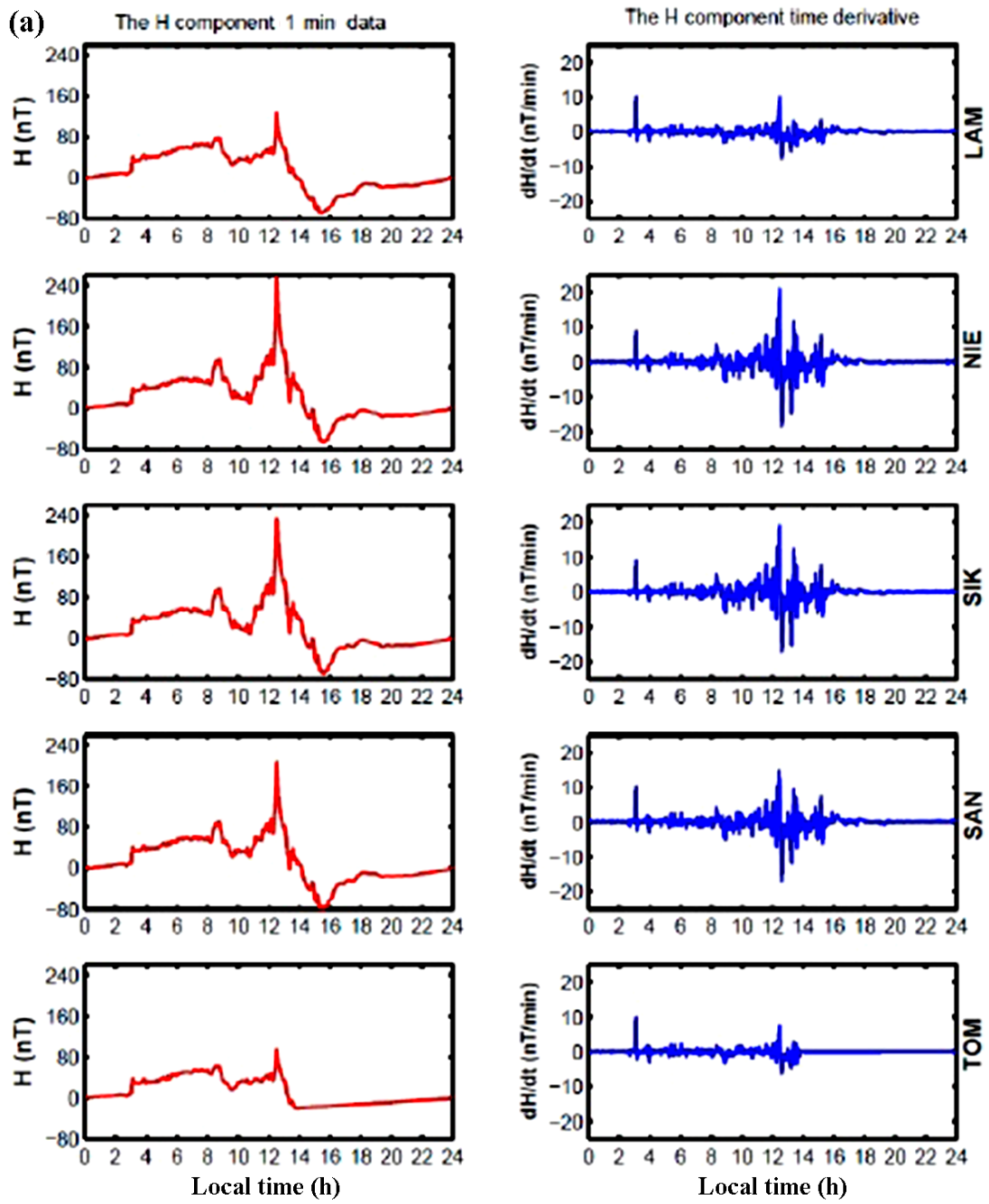

Figure 4.

amplify as we get close to the dip equator. In the $Z$ component the impulse effects decrease as we get close to the dip equator and reverse from Southern Hemisphere (positive) to the Northern Hemisphere (negative). Its largest amplitude is observed at SAN near the northern edge of the EEJ current sheet. For the $D$ component, negative impulses are observed and the amplitudes of these disturbances increase more and more as we progress from south (LAM) to north (TOM).

\subsection{Geo-electric field variations in response to the 17 February 1993 geomagnetic storm}

Figure 5 shows the Dst index and variations in $H$, time derivatives $\mathrm{d} H / \mathrm{d} t, \mathrm{~d} D / \mathrm{d} t$, and $\mathrm{d} Z / \mathrm{d} t$ and $E_{x}$ and $E_{y}$ components of the geo-electric field at SIK from 16 to 18 February 1993. $E_{x}$ (Fig. 5f) and $E_{y}$ (Fig. 5g) show daily variations (quasi $24 \mathrm{~h}$ period regular background signals of opposite phases). While $E_{x}$ decreases toward a minimum around noon, $E_{y}$ increases toward a maximum. Note that these daily variations are not analyzed in the present study. The quiet period daily variations in $E_{x}$ and $E_{y}$ are analyzed in another paper that is in preparation for a close future submission. It appears that $E_{x}$ and $E_{y}$ are affected by the rapid variations observed in geomagnetic field components.

The daily variations in $E_{x}$ and $E_{y}$ have been removed in order to better highlight the geo-electric field responses $E_{x d}$ (Fig. 5h) and $E_{y d}$ (Fig. 5i) to the geomagnetic storm. $E_{x d}$ and $E_{y d}$ show similar periodic variations to the geomagnetic field time derivatives. In particular during the geomagnetic storm on 17 February 1993, $E_{x d}$ and $E_{y d}$ exhibit sharp impulses as observed in the geomagnetic field time derivatives during the rapid phase of geomagnetic field variation. The signatures of the ssc around 03:00 LT and the brisk impulse at 11:00 LT in the geo-electric field components reflect that of the geomagnetic field time derivatives, in such a way that $E_{x d}$ and $\mathrm{d} D / \mathrm{d} t$ exhibit a similar pattern and sign; their effect in $E_{y d}$ and $\mathrm{d} H / \mathrm{d} t$ is also similar but with opposite signs. The brisk variations at 11:00 cause variations in the geo-electric 
(b)
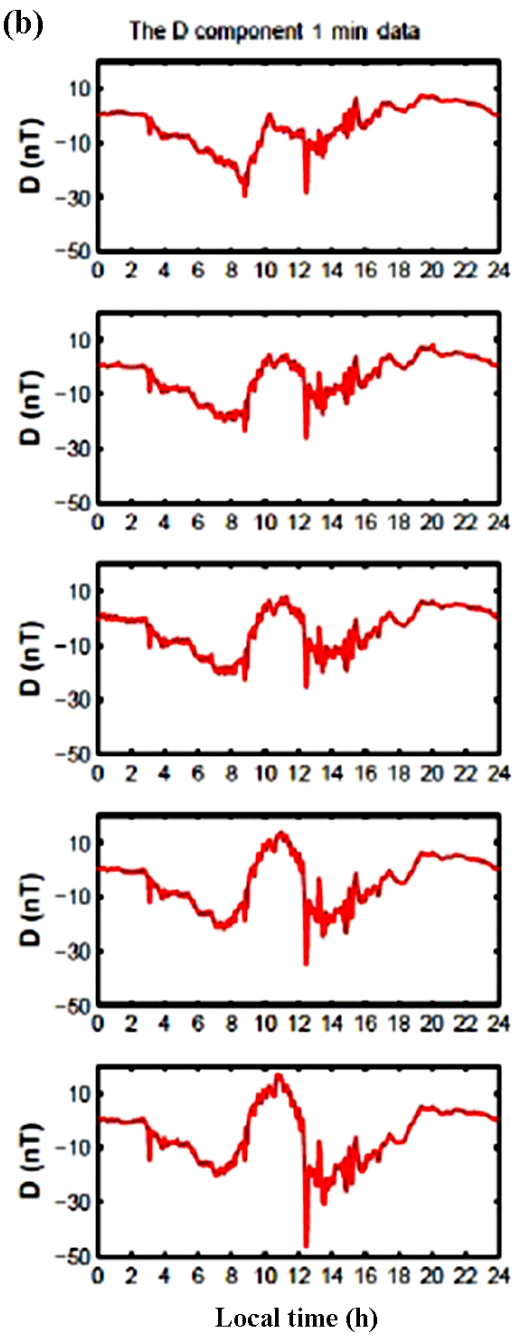
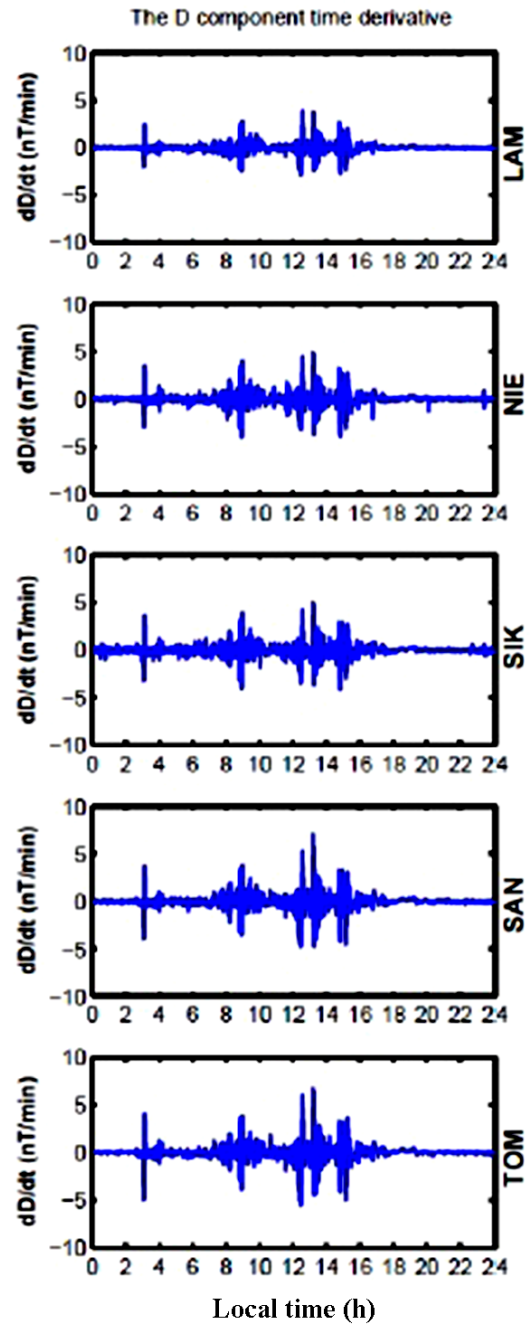

Figure 4.

field with crest-to-crest amplitudes of about $20 \mathrm{mV} \mathrm{km}^{-1}$ in $E_{x d}$ and $120 \mathrm{mV} \mathrm{km}^{-1}$ in $E_{y d}$. Note that the effects of the geomagnetic field brisk variations are observed in all the stations of the network. Their latitudinal dependence will be examined in Sect. 3.

\subsection{Geo-electric field variations in responses to the 4 April 1993 solar flare effect}

Figure 6 shows the variations in $H$ and $D$, the time derivatives $\mathrm{d} H / \mathrm{d} t$ and $\mathrm{d} D / \mathrm{d} t$ at KOU and the $E_{x}$ and $E_{y}$ components of the geo-electric field at LAM, KOR, MOP and TOM on 4 April 1993. Around 14:30 LT, an sfe is observed in the H component with a sharp impulse. The induction effects of the brisk variation due to this sfe on the time derivatives $\mathrm{d} H / \mathrm{d} t$ and $\mathrm{d} D / \mathrm{d} t$ of the magnetic field components and the $E_{x}$ and $E_{y}$ components of the geo-electric field are observed at different stations. The geo-electric field variations are particularly amplified at LAM, where the crest-to-crest amplitude of
$E_{x}$ and $E_{y}$ is, respectively, about 550 and $340 \mathrm{mV} \mathrm{km}^{-1}$. The sfe effects in $E_{y}$ decrease from LAM (south) to TOM (north); for $E_{x}$ the sfe effects decrease from LAM to MOP and increase at TOM. This latitudinal trend of the sfe signature in the geo-electric field variations likely reflects the influence of the subsolar point location at $5.13^{\circ} \mathrm{N}$, which is about $1.10^{\circ}$ south of LAM $\left(6.23^{\circ} \mathrm{N}\right)$. However, it is to be noted that the lateral resistivity may cause non-negligible changes from one place to another.

After the sfe, fluctuations of the $H$ and $D$ components are observed during the evening. These fluctuations also produce geo-electric field variations that are weaker than the sfe effects. 

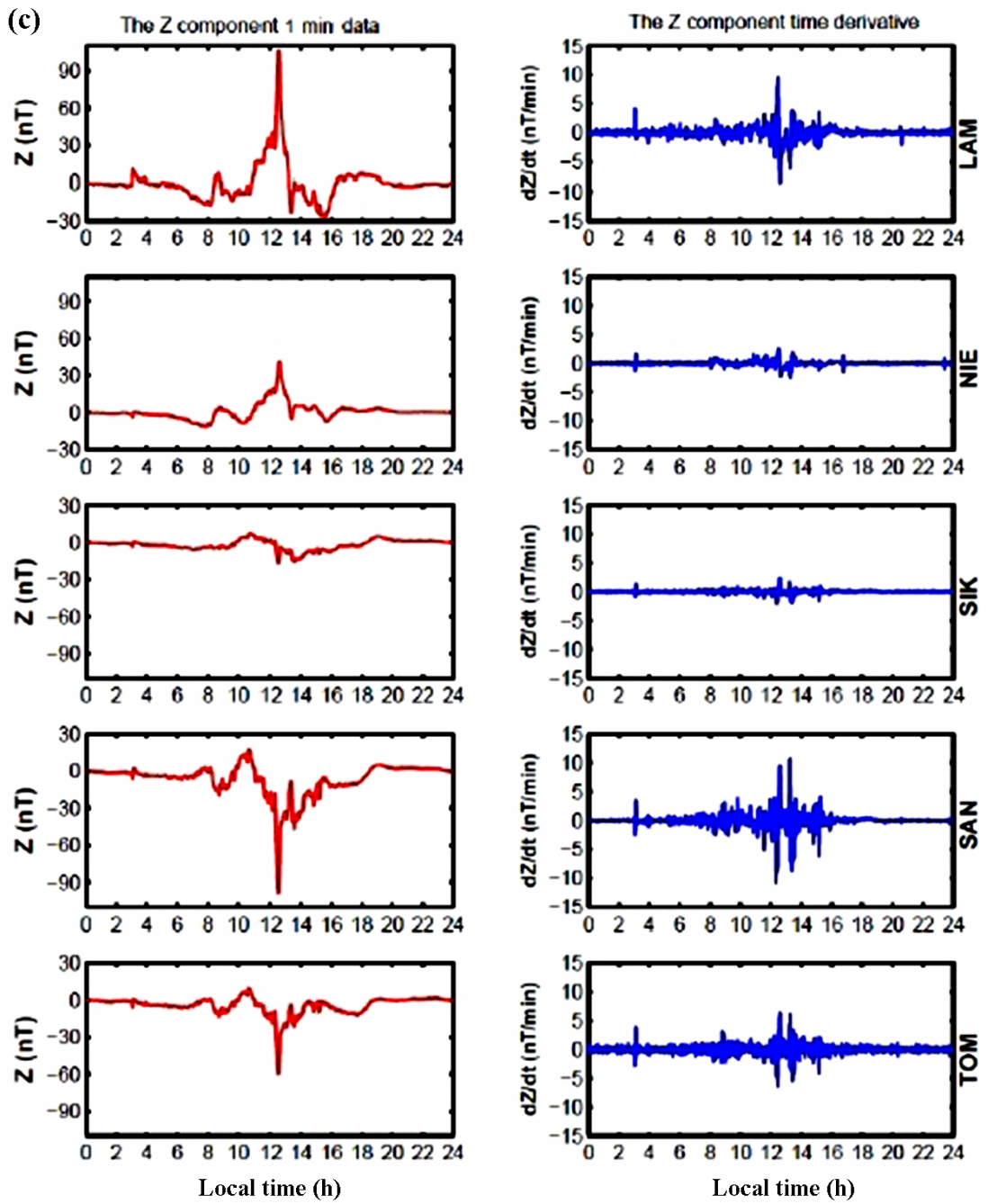

Figure 4. Geomagnetic field variations during the 17 February 1993 storm. Variations in the $H$ (panel a), $D$ (panel b) and $Z$ (panel c) component and its time derivative $\mathrm{d} Z / \mathrm{d} t$ at LAM, NIE, SIK, SAN and TOM.

\section{On the dependence of the geo-electric field intensity on the dip latitude}

The time derivatives $\mathrm{d} H / \mathrm{d} t$ and $\mathrm{d} D / \mathrm{d} t$ at SIK and the components $E_{x}$ and $E_{y}$ of the geo-electric field observed on 17 February 1993 at LAM, NIE, SIK, SAN and TOM are shown in Fig. 7a and b. In Fig. 7a, the geo-electric field components $E_{x}$ and $E_{y}$ exhibit clear diurnal background variations. The shapes and amplitudes of the $E_{x}$ and $E_{y}$ diurnal variations change from one station to another. Their amplitudes are clearly pronounced near the geomagnetic dip equator (NIE, SIK and SAN). As mentioned in Sect. 2.2, the diurnal variations in $E_{x}$ and $E_{y}$ will be deeply analyzed in an upcoming paper. After removing the daily background variations, the fluctuations of $E_{x}$ and $E_{y}$ due to the geomagnetic field brisk disturbances are shown in Fig. 7b. The signatures of the geomagnetic field disturbances are observed in the two components of the geo- electric field at the selected stations with a similar periodic pattern for respective components. However the amplitudes of the storm effects in $E_{x}$ and $E_{y}$ change drastically from one station to another. The responses of geo-electric field to the ssc of 03:00 LT at LAM are $E_{x}=-270 \mathrm{mV} \mathrm{km}^{-1}$ and $E_{y}=-150 \mathrm{mV} \mathrm{km}^{-1}$. For the impulse at 11:00 LT, the geo-electric field responses attain crest-to-crest amplitudes of $E_{x}=520 \mathrm{mV} \mathrm{km}^{-1}$ and $E_{y}=400 \mathrm{mV} \mathrm{km}^{-1}$ at LAM. At TOM, the ssc effects at 03:00 LT are $E_{x}=30 \mathrm{mV} \mathrm{km}^{-1}$ and $E_{y}=10 \mathrm{mV} \mathrm{km}^{-1}$; at 11:00 LT, $E_{x}=95 \mathrm{mV} \mathrm{km}^{-1}$ and $E_{y}=8 \mathrm{mV} \mathrm{km}^{-1}$. At NIE, the ssc effects at 03:00 LT are $E_{x}=30 \mathrm{mV} \mathrm{km}^{-1}$ and $E_{y}=8 \mathrm{mV} \mathrm{km}^{-1}$; at 11:00 LT, $E_{x}=$ $70 \mathrm{mV} \mathrm{km}^{-1}$ and $E_{y}=19 \mathrm{mV} \mathrm{km}^{-1}$. At SAN, the ssc effects at 03:00 LT are that $E_{x}$ and $E_{y}$ are very weak; at 11:00 LT, $E_{x}=10 \mathrm{mV} \mathrm{km}^{-1}$ and $E_{y}=14 \mathrm{mV} \mathrm{km}^{-1}$. Finally at SIK, close the EEJ center, the ssc effects at 03:00 LT are $E_{x}=8 \mathrm{mV} \mathrm{km}^{-1}$ and $E_{y}=30 \mathrm{mV} \mathrm{km}^{-1}$; at $11: 00 \mathrm{LT}$, $E_{x}=20 \mathrm{mV} \mathrm{km}^{-1}$ and $E_{y}=120 \mathrm{mV} \mathrm{km}^{-1}$. 

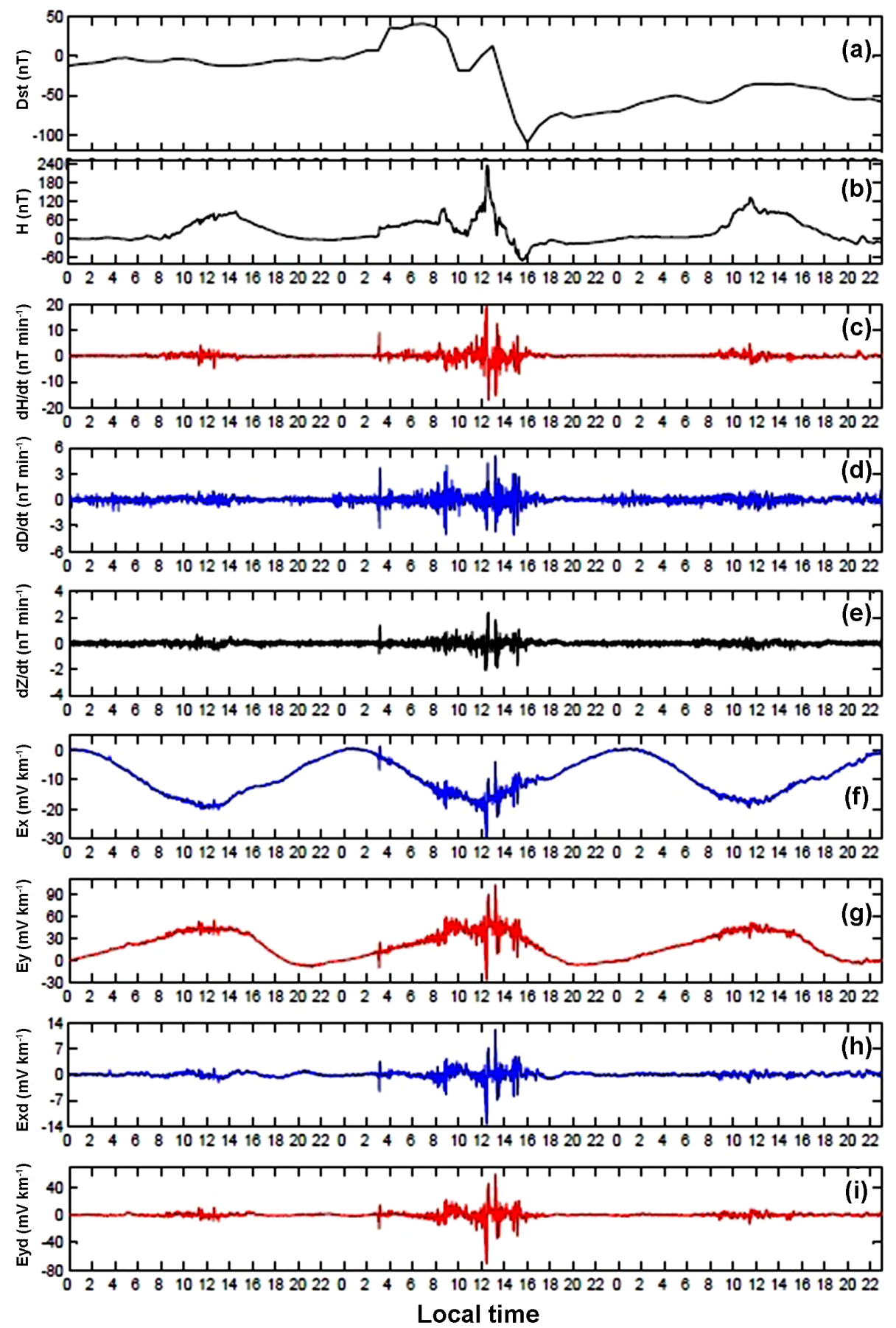

Figure 5. The geomagnetic disturbance effects observed on 16-18 February 1993 at SIK $\left(0.12^{\circ}\right.$ dip lat). Dst index (a), variations in $H$ (b), the time derivatives $\mathrm{d} H / \mathrm{d} t(\mathbf{c}), \mathrm{d} D / \mathrm{d} t(\mathbf{d})$ and $\mathrm{d} Z / \mathrm{d} t(\mathbf{e})$, total variations in the $E_{x}(\mathbf{f})$ and $E_{y}(\mathbf{g})$ component of the geo-electric field, and the geomagnetic disturbance effects $E_{x d}(\mathbf{h})$ and $E_{y d}$ (i) in the geo-electric field.

It is to be noted that the most important impulses in the geo-electric field variations are associated with brisk variations in the geomagnetic field. Indeed, in addition to the ssc effects, the impulses between about 03:00 to 14:00 LT correspond to the brisk variations in the time derivatives $\mathrm{d} D / \mathrm{d} t$ and $\mathrm{d} H / \mathrm{d} t$ in the same time interval. During the main phase of the storm, additional fluctuations of weaker intensity are also observed in the time interval from 15:00 to 16:00 LT. 

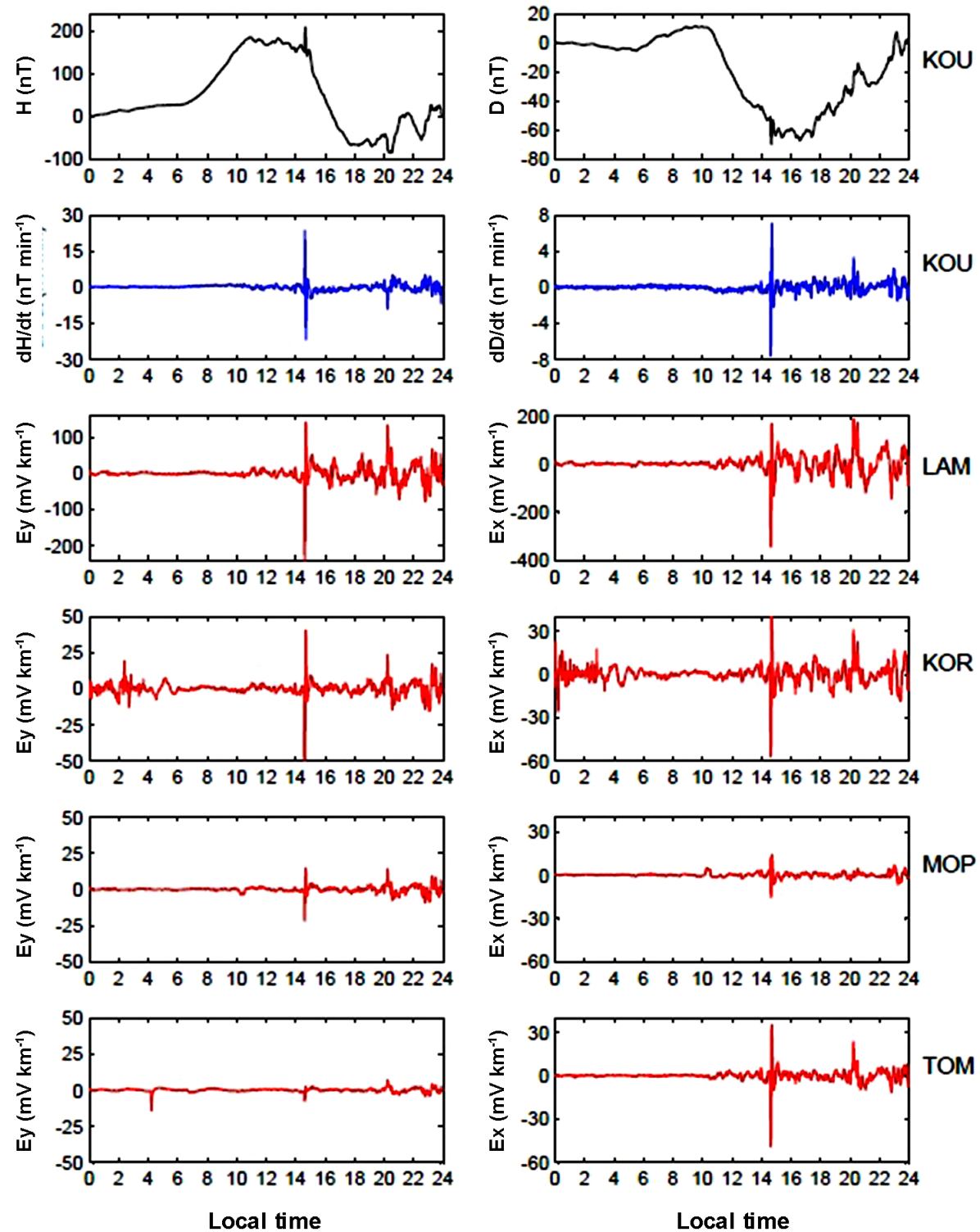

Figure 6. Geo-electric field variations during the 17 February 1993 storm. The top panels show the time derivatives of $H$ (left) and $D$ (right) and the other panels show variations in the $E_{x}$ (left column) and $E_{y}$ (right column) at LAM, NIE, SIK, SAN and TOM.

\section{Discussion}

The present study analyzes geomagnetic field and geoelectric field variations observed in West Africa during the IEEY campaign. The observations demonstrate that intense space weather events are potential sources of electric inductions within the Earth at low latitudes. The ssc and sfe are intense and rapid geomagnetic field variations in time. The effectiveness of the induction effects of these geomagnetic field variations at low latitudes is clearly shown through the geo-electric field observations. Furthermore the most intense induction effects are likely associated with these brisk impulses in the geomagnetic field variations as shown through our observations. Indeed, the moderate geomagnetic storm that occurred on 17 February 1993, with the minimum Dst index of $-110 \mathrm{nT}$, produced non-negligible geoelectric field variations during the ssc phase. At LAM, the geo-electric field responses to the daytime impulse components are $E_{x}=520 \mathrm{mV} \mathrm{km}^{-1}$ and $E_{y}=400 \mathrm{mV} \mathrm{km}^{-1}$. On the other hand, the geo-electric field variations associated with the sfe of 4 April 1993 also show special amplifications at LAM, where the crest-to-crest amplitude of $E_{x}$ and $E_{y}$ is, respectively, about 550 and $340 \mathrm{mV} \mathrm{km}^{-1}$. These observations clearly confirm the possibility of non-negligible GIC at low latitudes, in case of severe space weather events, as demonstrated by Kappenman (2003), Ngwira et al. (2013) and Carter et al. (2015). 
(a)
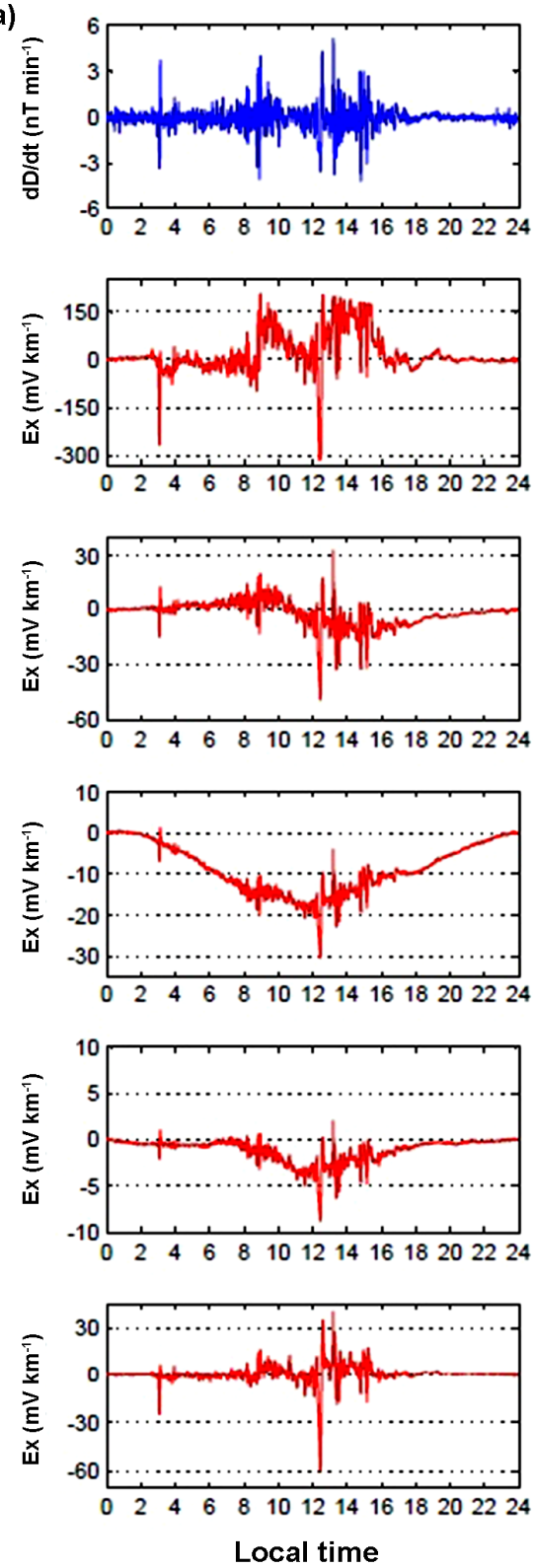
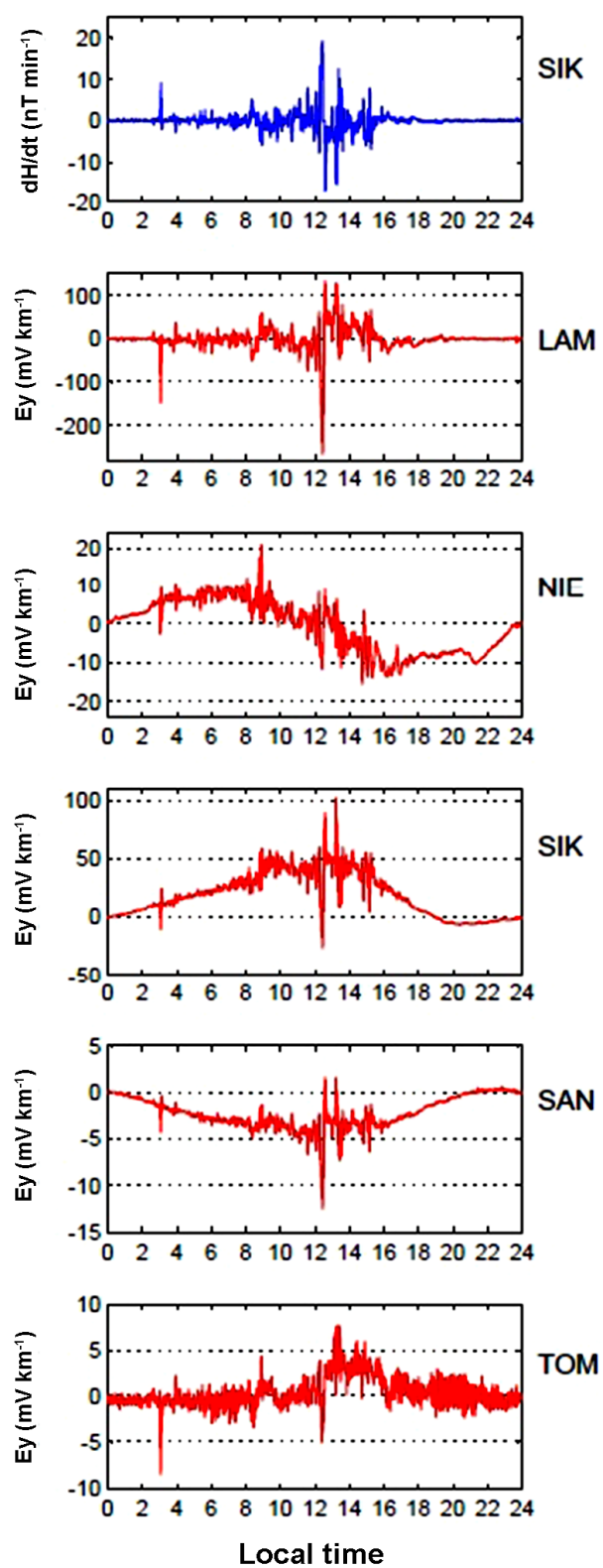

Figure 7.

Given the latitudinal dependence of the time derivatives of the geomagnetic field, the daytime eastward induction effects should be expected to increase as we get close to the geomagnetic dip equator. The observations show that the magnitudes of the geo-electric field response to the geomagnetic disturbances depend on the observational locations. However this dependence does not show any special latitudinal trend for the 17 February geomagnetic storm. The amplitudes of the geo-electric field variations at LAM and TOM are totally different, the amplitudes at LAM are significantly more elevated than that at TOM. The drastic change in the storm time geo-electric field amplitude from one site to another may be related to the lateral variations in the Earth resistivity (Vas- sal et al., 1998). For the sfe effects, the amplitudes tend to decrease from south to north for the two components with the strongest amplitude at LAM and weakest amplitudes of $E_{y}$ at TOM and $E_{x}$ at MOP. Note that the amplitude of $E_{x}$ is higher at TOM than at MOP. The latitudinal trend of the sfe signature in the geo-electric field variations may be related to the location of the subsolar point, which is located on the southern side of the chain of stations (at about $5.13^{\circ} \mathrm{N}$ on 4 April). This trend does not show any special increase in the geo-electric field amplitude near the dip equator. A priori, this observation contrasts with the latitudinal behavior of the sfe, which increases when we get close to the dip equator (Rastogi et al., 1999), as for most of the geomagnetic field 
(b)
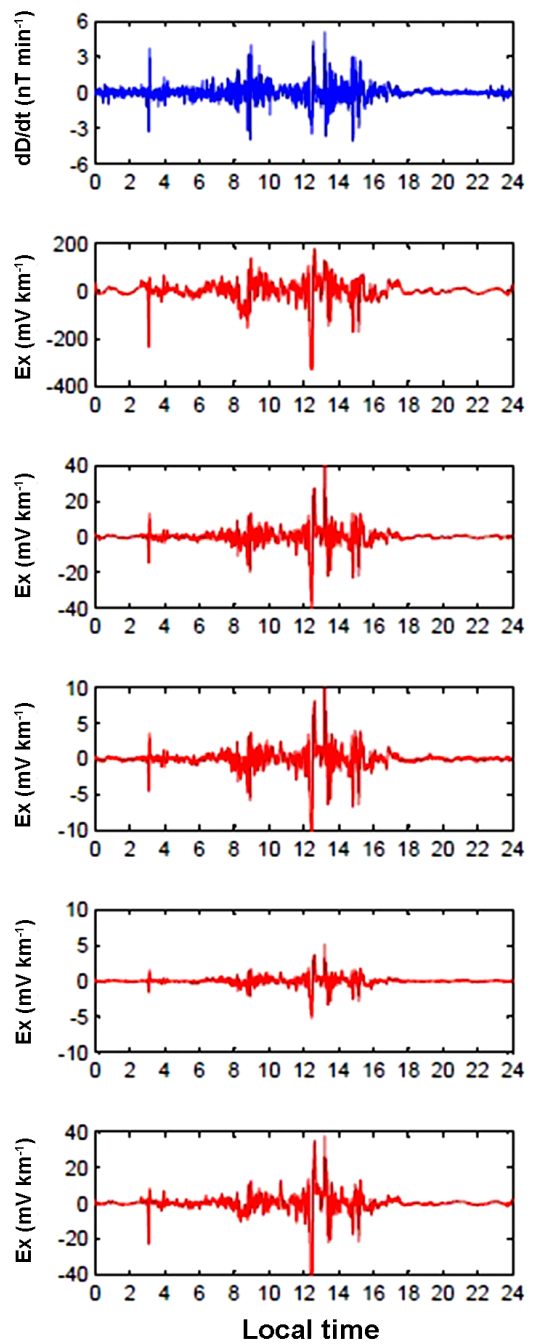
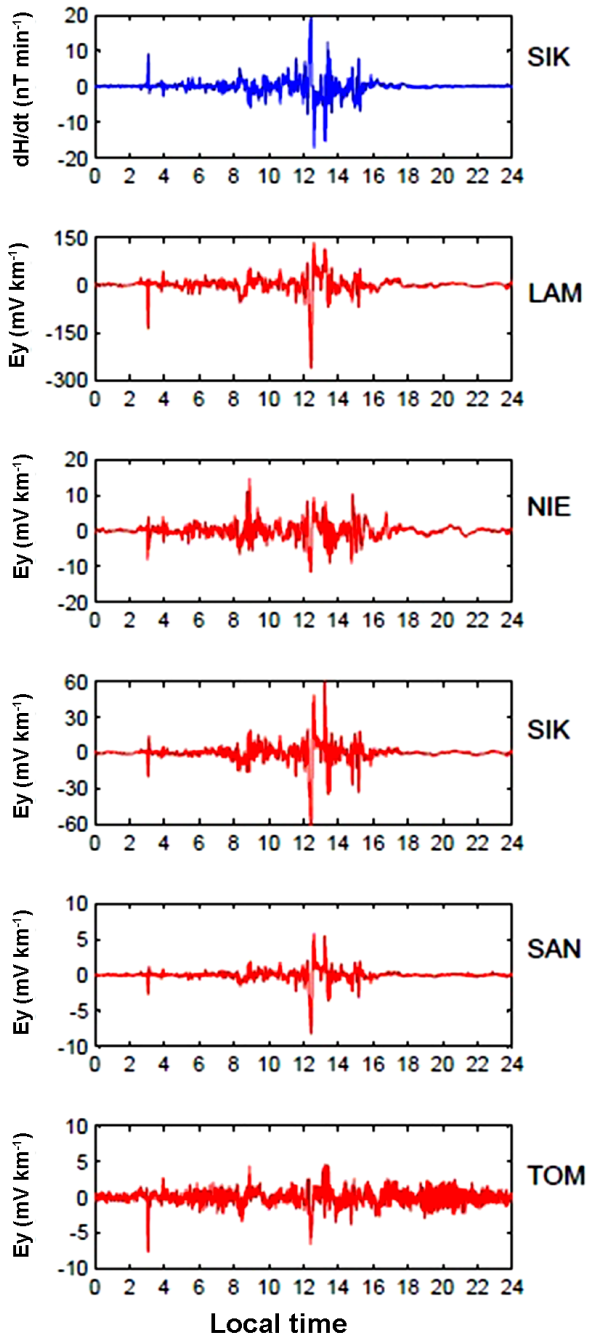

Figure 7. (a) Geo-electric field variations on 17 February 1993. The top panels show the time derivatives of $H$ (left) and $D$ (right) and the other panels show variations in the $E_{x}$ (left column) and $E_{y}$ (right column) at LAM, NIE, SIK, SAN and TOM. The geomagnetic field disturbance effects are superimposed on the daily regular variation in $E_{x}$ and $E_{y}$ during the geomagnetic storm. (b) Same as Fig. 7a, with the daily variations removed from $E_{x}$ and $E_{y}$.

disturbances. This increase is due to the high electrical conductivity (Cowling conductivity) in the EEJ belt. Concerning the latitudinal trend of the sfe signature in the geo-electric field variations, the difference in the lateral resistivity from one location to another may also contribute. Different lateral resistivity possibly underlies the fact that $E_{x}$ has a higher amplitude at TOM than at MOP and also that the amplitudes of $E_{x}$ and $E_{y}$ are considerably more elevated at LAM than elsewhere for the sfe signature as well as for that of the ssc. Vassal et al. (1998) analyzed the lateral variations in the Earth resistivity from LAM to TOM. They considered two models of stratified Earth corresponding to the average resistive structure of the two tectonic provinces across the area of concern: a sedimentary basin in the north and a cratonic shield in the south. The apparent resistivity computed according to those models was found to be stronger in the cratonic shield than in the sedimentary basin. However the real structure of the Earth resistivity in the area may be different from this simple scenario.

It is evident that the level of geomagnetically induced effects at low latitudes, in terms of amplitude, cannot be compared with that at high latitudes (Ngwira et al., 2013). However, the present study, based on a moderate geomagnetic storm and solar flare, confirms that there exists a risk of nonnegligible GICs in conductive media at low latitudes during the brisk phases of space weather events like sscs and sfes, as noticed by Kappenman (2003), Ngwira et al. (2013) and Carter et al. (2015). Indeed, in the light of the high amplitudes of the geo-electric field variations at LAM, the threat of intense geomagnetically induced current can be important for highly conductive systems that are located in the vicinity of the EEJ. In addition, the latitudinal variations in the ge- 
omagnetic field time derivatives confirm the possibility of a potentially strong induction effect due the EEJ near the geomagnetic dip equator.

Although the analyses of the diurnal variation in the geoelectric field were not the purpose of this work, the observations clearly exhibit daily variations in $E_{x}$ and $E_{y}$, which can have different behavior from one station to another. The amplitudes of the daily variations in $E_{x}$ and $E_{y}$ are particularly enhanced at $\operatorname{SIK}\left(0.12^{\circ} \mathrm{N}\right.$ dip lat $)$, the closest station of the network to the geomagnetic dip equator in 1993. Special attention is given to this aspect in an upcoming work that will be focused on large geomagnetic quiet-time data.

\section{Data availability}

The Dst index data were downloaded from the website of the WDC for Geomagnetism (2017), Kyoto Dst index service: http://wdc.kugi.kyoto-u.ac.jp/dst_final/index.html.

The geomagnetic and geo-electric field data belong to the IRD (Institut de Recherche pour le Developpement) and to the IPGP (France) and Universite de Cocody (Cote d'Ivoire). These research institutions collaborated in the IEEY program in West Africa. The data are public. A CD copy of data can be obtained if required by contacting the corresponding author (vafid@yahoo.fr).

Acknowledgements. The records of geomagnetic field and the geoelectric field variations were created by the French research institutions IRD (Institut de Recherche pour le Developpement) and IPGP (Institut de Physique du Globe de Paris), in collaboration with Université de Cocody (Côte d'Ivoire) during the International Equatorial Electrojet Year (IEEY).

The topical editor, E. Yizengaw, thanks two anonymous referees for help in evaluating this paper.

\section{References}

Amory-Mazaudier, C., Vila, P., Achache, J., Achy Seka, A., Albouy, Y., Blanc, E., Boka, K., Bouvet, J., Cohen, Y., Dukhan, M., Doumouya, V., Fambitakoye, O., Gendrin, R., Goutelard, C., Hamoudi, M., Hanbaba, R., Houngninou, E., Huc, C., Kakou, K., Kobea-Toka, A., Lassudrie-Duchesne, P., Mbipom, E., Menvielle, M., Ogunade, S. O., Onwumechili, C. A., Oyinloye, J. A., Rees, D., Richmond, A., Sambou, E., Schmuker, E., Tirefort, J. L., and Vassal, J.: International equatorial electrojet year: the African sectorm, Revista Brasileira de Geofisica, 11, 303-317, 1993.

Arora, B. R., Mahashabde, M. V., and Kalra, R.: Indian IEEY geomagnetic observational program and some preliminary results, Brazilian Journal of Geophysics, 11, 365-384, 1993.

Blanc, E. and Houngninou, E.: Typical disturbances of the daytime equatorial $\mathrm{F}$ region observed with a high-resolution $\mathrm{HF}$ radar, Ann. Geophys., 16, 721-730, doi:10.1007/s00585-998-0721-6, 1998.
Blanc, M. and Richmond, A. D.: The Ionospheric Disturbance Dynamo, J. Geophys. Res., 85, 1669-1686, 1980.

Carter, B. A., Yizengaw, E., Pradipta, R., Halford, A. J., Norman, R., and Zhang, K.: Interplanetary shocks and the resulting geomagnetically induced currents at the equator, Geophys. Res. Lett., 42, 6554-6559, doi:10.1002/2015GL065060, 2015.

Doumouya, V., Vassal, J., Cohen, Y., Fambitakoye, O., and Menvielle, M.: Equatorial electrojet at African longitudes: first results from magnetic measurements, Ann. Geophys., 16, 658666, doi:10.1007/s00585-998-0658-9, 1998.

Ducruix J., Courtillot, V., and Le Mouel, J. L.: On the induction effects associated with the equatorial electrojet, J. Geophys. Res., 82, 335-351, 1977.

Fambitakoye O.: Effets induits par l'électrojet équatorial au centre de l'Afrique, Ann. Geophys., 29, 149-169, 1973.

Fambitakoye, O., Menvielle, M., and Mazaudier, C.: Global Disturbance of the Transient Magnetic Field Associated to Thermospheric Storm Winds on March 23, 1979, J. Geophys. Res., 95, 209-218, 1990.

Kappenman, J. G.: Storm sudden commencement events and the associated geomagnetically induced current risks to groundbased systems at low-latitude and mid latitude locations, Space Weather, 1, 1016, doi:10.1029/2003SW000009, 2003.

Ngwira, C. M., Pulkkinen, A., McKinnell, L.-A., and Cilliers, P. J.: Improved modeling of geomagnetically induced currents in the South African power network, Space Weather, 6, S11004, doi:10.1029/2008SW000408, 2008.

Ngwira, C. M., Pulkkinen, A., Wilder, F. D., and Crowley, G.: Extended study of extreme geo-electric field event scenarios for geomagnetically induced current applications, Space Weather, 11, 121-131, doi:10.1002/swe.20021, 2013.

Pirjola, R.: Geomagnetically induced currents during magnetic storms, IEEE T. Plasma Sci., 28, 1869-1873, 2000.

Pirjola, R.: Review on the calculation of surface electric and magnetic fields and of geomagnetically induced currents in groundbased technological systems, Surv. Geophys., 23, 71-90, 2002.

Pirjola, R., Kauristie, K., Lappalainen, H., Viljanen, A., and Pulkkinen, A.: Space weather risk, Space Weather, 3, S02A02, doi:10.1029/2004SW000112, 2005.

Pulkkinen, A.: Geomagnetic Induction During Highly Disturbed Space Weather Conditions: Studies of Ground Effects, Contributions, Finn. Meteorol. Inst., Helsinki, Finland, 42, 164 pp., 2003.

Pulkkinen, A., Viljanen, A., Pajunpaää, K., and Pirjola, R.: Recordings and occurrence of geomagnetically induced currents in the Finnish natural gas pipeline network, J. Appl. Geophys., 48, 219231, 2001.

Pulkkinen, A., Amm, O., Viljanen, A., and BEAR Working Group: Ionospheric equivalent current distributions determined with the method of spherical elementary current systems, J. Geophys. Res., 108, 1053, doi:10.1029/2001JA005085, 2003a.

Pulkkinen, A., Thomson, A., Clarke, E., and McKay, A.: April 2000 geomagnetic storm: ionospheric drivers of large geomagnetically induced currents, Ann. Geophys., 21, 709-717, doi:10.5194/angeo-21-709-2003, 2003b.

Pulkkinen, A., Pirjola, R., and Viljanen, A.: Determination of ground conductivity and system parameters for optimal modeling of geomagnetically induced current flow in technological systems, Earth Planets and Space, 59, 999-1006, 2007. 
Rastogi, R. G., Pathan, B. M., Rao, D. R. K., Sastry, T. S., and Sastri, J. H.: Solar flare effects on the geomagnetic elements during normal and counter electrojet periods, Earth Planets Space, 51, 947-957, 1999.

Torta, J. M., Serrano, L., Regué, J. R., Sánchez, A. M., and Roldán, E.: Geomagnetically induced currents in a power grid of northeastern Spain, Space Weather, 10, S06002, doi:10.1029/2012SW000793, 2012.

Trivedi, N. B., Vitorello, I., Kabata, W., Dutra, S. L. G., Padilha, A. L., Bologna, M. S., de Pádua, M. B., Soares, A. P., Luz, G. S., Pinto, F. de A., Pirjola, R., and Viljanen A.: Geomagnetically induced currents in an electric power transmission system at low latitudes in Brazil: A case study, Space Weather, 5, S04004, doi:10.1029/2006SW000282, 2007.

Vassal, J., Menvielle, M., Cohen, Y., Dukhan, M., Doumouya, V., Boka, K., and Fambitakoye, O.: A study of transient variations in the Earth's electromagnetic field at equatorial electrojet latitudes in western Africa (Mali and the Ivory Coast), Ann. Geophys., 16, 677-697, doi:10.1007/s00585-998-0677-6, 1998.

Vila, P., Rees, D., Merrien, P., and Kone, E.: Fabry-Perot interferometer measurements of neutral winds and F2 layer variations at the magnetic equator, Ann. Geophys., 16, 731-737, doi:10.1007/s00585-998-0731-4, 1998.
WDC for Geomagnetism: Dst index data, available at: http://wdc. kugi.kyoto-u.ac.jp/dst_final/index.html, last access: 2 January 2017.

Wik, M., Viljanen, A., Pirjola, R., Pulkkinen, A., Wintoft, P., and Lundstedt, H.: Calculation of geomagnetically induced currents in the $400 \mathrm{kV}$ power grid in southern Sweden, Space Weather, 6, S07005, doi:10.1029/2007SW000343, 2008.

Wik, M., Pirjola, R., Lundstedt, H., Viljanen, A., Wintoft, P., and Pulkkinen, A.: Space weather events in July 1982 and October 2003 and the effects of geomagnetically induced currents on Swedish technical systems, Ann. Geophys., 27, 1775-1787, doi:10.5194/angeo-27-1775-2009, 2009.

Zaka, K. Z., Kobea, A. T., Doumbia, V., Richmond, A. D., Maute, A., Mene, N. M., Obrou, O. K., Assamoi, P., Boka, K., Adohi, J.-P., and Amory-Mazaudier, C.: Simulation of electric field and current during the 11 June 1993 disturbance dynamo event: Comparison with the observations, J. Geophys. Res., 115, A11307, doi:10.1029/2010JA015417, 2010. 